LA-UR-97- -2991

CONF-970707--

Los Alamos National Laboratory is operated by the University of California for the United States Department of Energy under contract W-7405-ENG-36

TITLE: DETERMINATION OF THE RESPONSE OF PENTAERYTHRITOL TETRANITRATE TO STATIC HIGH PRESSURE UP TO $4.2 \mathrm{GPa}$ BY NEUTRON DIFFRATION

AUTHOR: Jerry J. Dick and Robert B. von Dreele

LANL, Los Alamos, NM 87545

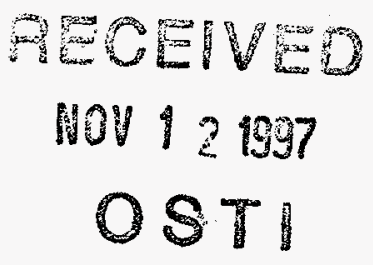 \\ PECENED \\ NOV 121997 \\ OSTI
}

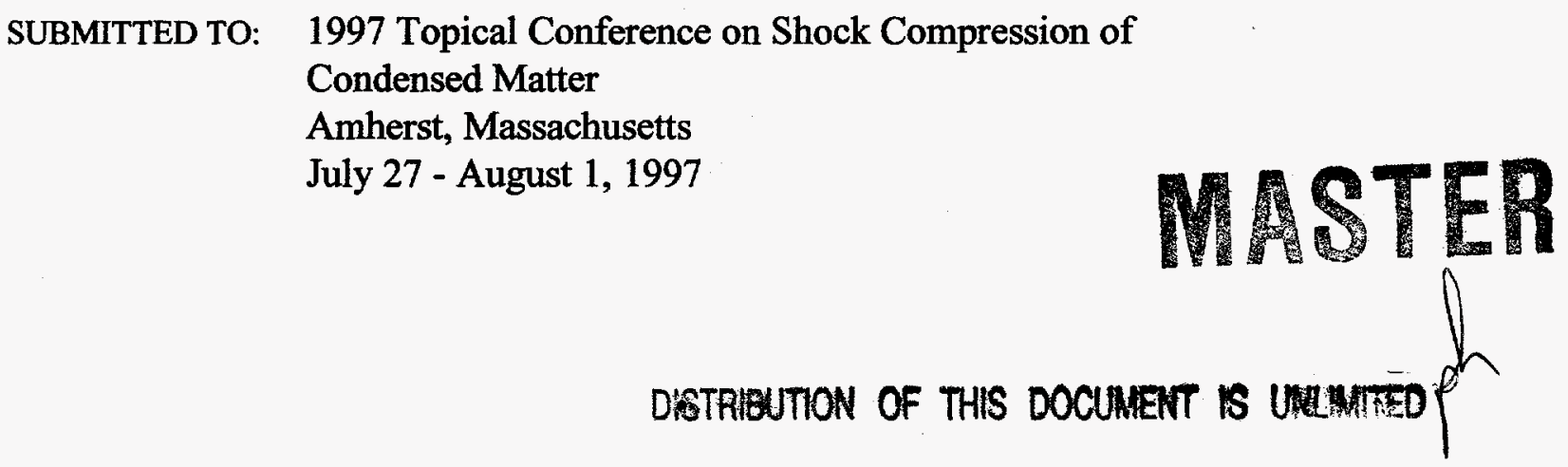

By acceptance of this article, the publisher recognizes that the U.S. Government retains a nonexclusive, royalty-free license to publish or reproduce the published form of this contribution, or to allow others to do so, for U.S. Government purposes.

The Los Alamos National Laboratory requests that the publisher identify this article as work performed under the auspices of the U.S. Department of Energy. 


\section{DISCLAMIIR}

Portions of this document may be illegible in electronic image products. Images are produced from the best avallable original document. 


\section{DISCLAIMER}

This report was prepared as an account of work sponsored by an agency of the United States Government. Neither the United States Government nor any agency thereof, nor any of their employees, make any warranty, express or implied, or assumes any legal liability or responsibility for the accuracy, completeness, or usefulness of any information, apparatus, product, or process disclosed, or represents that its use would not infringe privately owned rights. Reference herein to any specific commercial product, process, or service by trade name, trademark, manufacturer, or otherwise does not necessarily constitute or imply its endorsement, recommendation, or favoring by the United States Government or any agency thereof. The views and opinions of authors expressed herein do not necessarily state or reflect those of the United States Government or any agency thereof. 


\title{
DETERMINATION OF THE RESPONSE OF PENTAERYTHRITOL TETRANITRATE TO STATIC HIGH PRESSURE UP TO 4.2 GPa BY NEUTRON DIFFRACTION. *
}

\author{
J. J. Dick ${ }^{a}$ and R. B. von Dreele ${ }^{b}$ \\ ${ }^{a}$ Group DX-1, MS P952, ${ }^{b} M L N S C, M S H 805$, \\ Los Alamos National Laboratory, Los Alamos, New Mexico 87545
}

Neutron powder diffraction experiments were performed on pentaerythritol tetranitrate explosive up to $4.28 \mathrm{GPa}$. For deuterated samples the changes in lattice parameters, intramolecular torsional angles and molecular rotation were measured. The lattice parameter changes were different from those observed in protonated samples. However, there is no evidence of a phase transition or change in molecular symmetry.

\section{INTRODUCTION}

Some orientations of pentaerythritol tetranitrate (PETN) crystals have anomalously high shock initiation sensitivity around 4 to $5 \mathrm{GPa}$. Anomalous luminescent emission and initiation of detonation have been observed for two orientations of single crystals of (PETN) in shock experiments near $4 \mathrm{GPa}$.(1) The crystals were more sensitive at $4.2 \mathrm{GPa}$ than at $8.5 \mathrm{GPa}$. From the data available it was not clear what was responsible for this anomaly.

There have been observations of this anomaly by other workers. An unexpected, rapid rise in longitudinal stress after an induction time of about $0.3 \mu$ s was noted in an impact-face, quartzgauge experiment at $4.1 \mathrm{GPa}$ in a [110] crystal by P. M. Halleck and J. Wackerle.(2) This was the first published work on this subject. Recently observations of the induction time for onset of luminescent emission in [110] crystals was obtained over the stress range of 3.5 to $12 \mathrm{GPa}$ by $\mathrm{D}$. Spitzer.(3) The minimum induction time was observed at about $5 \mathrm{GPa}$; induction times are longer for shock stresses both smaller and larger than 5

*Work performed under the auspices of the U. S. Department of Energy
GPa. Their results are consistent with our observations in Ref.1.

There is a report of reaction propagation rates in polycrystalline PETN in a diamond anvil cell that may be related to the anomaly.(4) The reaction propagation rate was measured from 2 to 20 GPa. A local peak in rate was observed at about $5 \mathrm{GPa}$, about the same location as the peak shock sensitivity for [110] crystals at low shock stresses. It is not clear what the connection is between the two kinds of measurements. In the diamond anvil cell the propagation rates are more than an order of magnitude slower than shock speeds and apparently represent deflagrations at high pressure. In addition, they performed Fourier transform infrared (FTIR) spectral measurements that they interpreted as caused by an asymmetric deformation of the molecule to a lower symmetry conformation on compression.

In order to answer the question if any phase transition or change in molecular conformation is associated with the anomalous sensitivity at 4 to $5 \mathrm{GPa}$, neutron powder diffraction data under pressure was obtained using the neutron beam at 1 


\section{EXPERIMENTAL TECHNIQUE}

Static high pressure was obtained using "ParisEdinburgh" cell(5) that is capable of hydrostatic pressures up to $10 \mathrm{GPa}$. Previously data has been obtained on nitromethane to $5.5 \mathrm{GPa}$.(6) $\mathrm{Ni}$ tromethane is an explosive molecule $\mathrm{CH}_{3} \mathrm{NO}_{2}$. It is much smaller than PETN $\mathrm{C}_{5} \mathrm{H}_{8} \mathrm{~N}_{4} \mathrm{O}_{12}$ currently under study. In PETN there is a central carbon with a tetrahedron of 4 carbons around it. To each of the 4 carbons is bonded 2 hydrogens and an $\mathrm{ONO}_{2}$ group. In order to reduce background counts from incoherent scattering, PETN was initially studied in fully deuterated form $d_{8}$-PETN, more than $99 \mathrm{~mol} \%$ deuterium. A mixture of 47 $\mathrm{mg}$ of $\mathrm{d}_{8}$-PETN and $23 \mathrm{mg}$ of $\mathrm{NaCl}$ was pressed into a pellet $4 \mathrm{~mm}$ in diameter and $3.5 \mathrm{~mm}$ thick. The pellet had a void content of about $15 \%$. This pellet was placed in a slurry of crushed aerogel and Fluorinert-70 (3-M Company) in the cavity of the pressure cell. The cavity between the gasketed tungsten carbide anvils is $8.5 \mathrm{~mm}$ in diameter. Upon compression the Fluorinert-70 infiltrated the pellet providing a hydrostatic medium. The $\mathrm{NaCl}$ provides the pressure standard.

Diffraction patterns were obtained in about 12 hours at each of 5 pressures from 0.154 to $4.28 \mathrm{GPa}$. Structure refinements were performed via the Rietveld method using the GSAS suite of computer programs.(7) "Soft" constraints were included for all near-neighbor interatomic distances; the torsion angles were not affected by these constraints. Final residuals, Rwp, of ca. $2 \%$ were obtained for all refinements.

\section{EXPERIMENTAL RESULTS AND DISCUSSION}

A neutron powder diffraction for $d_{8}$-PETN at $0.154 \mathrm{GPa}$ is shown in Fig. 1. There is no change in symmetry from ambient. It is still in space group $\mathrm{P} 4 \overline{2}_{1} \mathrm{c}$ and remains there to $4.28 \mathrm{GPa}$. Therefore, the molecule has not undergone any asymmetric deformation. The FTIR experiments published in Ref.4 showed apparent asymmetric deformation of the molecule. In that case a thin film of PETN was compressed against a $\mathrm{KBr}$ pellet in a diamond anvil cell. The resultant nonhydrostatic stresses may have caused the spectrum changes that were interpreted as due to asymmet-

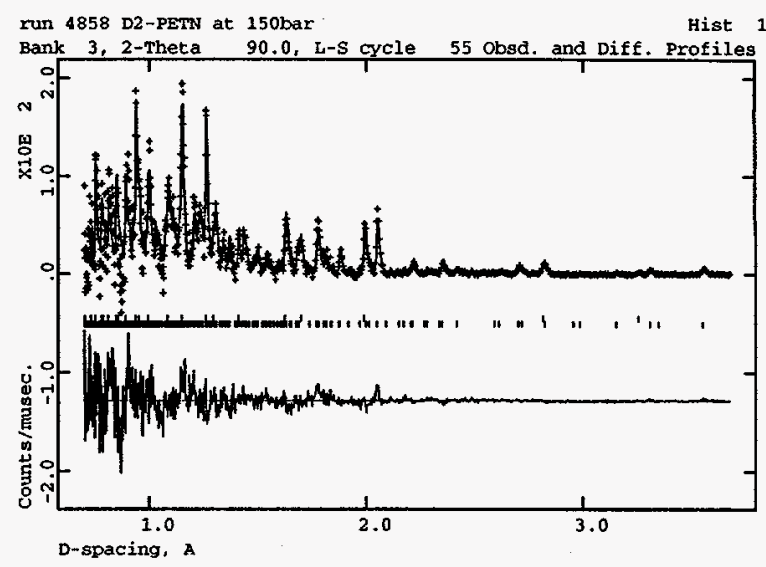

FIGURE 1. Time-of-flight neutron powder diffraction data for $d_{8}$-PETN at $0.154 \mathrm{GPa}$. The observed data have been normalized by the incident intensity; the computed background from the Rietveld refinement has been subtracted. The upper curve is the fit to the data. The lower curve is the difference between the fit and the measured counts. Between the curves there are two sets of bars. The upper set marks the position of $\mathrm{NaCl}$ peaks, and the lower set marks the position of PETN peaks.

ric deformation of the molecule.

The pressure vs volume compression data for PETN are shown in Fig. 2. The compression for deuterated PETN appears to be the same as for $x$-ray data for protonated $\operatorname{PETN}(8)$ in this pressure range within experimental precision. While the apparent volume decrease of the unit cell is the same for both, the unit cell deformation is different for protonated and deuterated PETN. This is shown in the lattice parameter changes with pressure for the two types in Fig. 3. The values at zero pressure are from the x-ray and neutron data refinement reported by Conant et al.(9) From xray spectra they found that the lattice parameters for protonated and deuterated PETN were the same. However, with pressure the lattice parameters vary differently. For deuterated PETN the a-axis shortens more and the c-axis shortens less than protonated PETN. It does so in such a way that the unit cell volumes at a given pressure are the same within experimental precision.

There are significant changes in the molecular conformation with compression. Torsional angle changes require the least energy in accomo- 


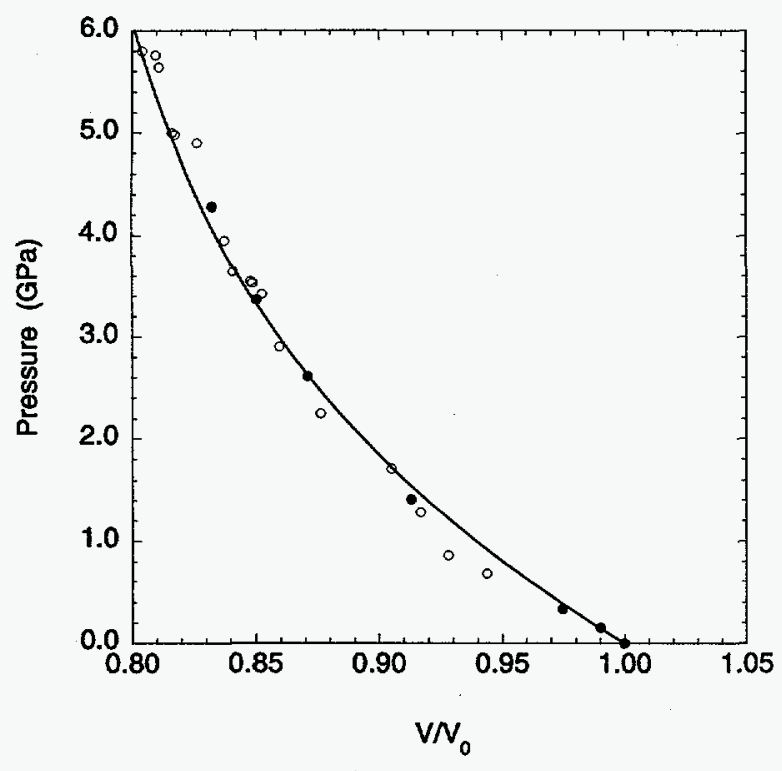

FIGURE 2. Pressure vs volume data for PETN. The open circles are x-ray data from Olinger et al. for protonated PETN, and the closed circles are from neutron diffraction of $d_{8}$-PETN. The solid line is a fit to the protonated data given in the article by Olinger et al..

dating the closer approaches between neighboring molecules. The angle changes are as large as $8^{\circ}$. The changes for the $\mathrm{C}-\mathrm{C}, \mathrm{C}-\mathrm{O}$, and $\mathrm{O}-\mathrm{N}$ torsions are displayed in Fig. 4. The angle changes are referenced to zero at the first measured point 0.154 GPa since the conformation of $\mathrm{d}_{8}-\mathrm{PETN}$ at zero pressure is not known with certainty. It is interesting to note that both the $\mathrm{C}-\mathrm{C}$ and $\mathrm{C}-\mathrm{O}$ torsional angle changes go through a minimum near 1.4 GPa. The changes from the angle at 0.154 GPa are $8^{\circ}$ and $4^{\circ}$, respectively. As noted earlier, these changes are symmetric within the molecule. Precision of the angle measurement is about $0.25^{\circ}$.

In addition to the intramolecular conformation changes, the entire molecule performs a rotation about the $c$ axis. These rotations are shown in Fig. 5 . It changes by a total of $2^{\circ}$. It is interesting to note that this angle change goes through a local maximum at $1.4 \mathrm{GPa}$ where the $\mathrm{C}-\mathrm{C}$ and $\mathrm{C}-\mathrm{O}$ torsional angle changes go through a minimum. As the lattice parameters are reduced under compression, the intermolecular forces get stronger. The intramolecular conformation changes and molecular rotation act in concert so as to minimize the energy of interaction.

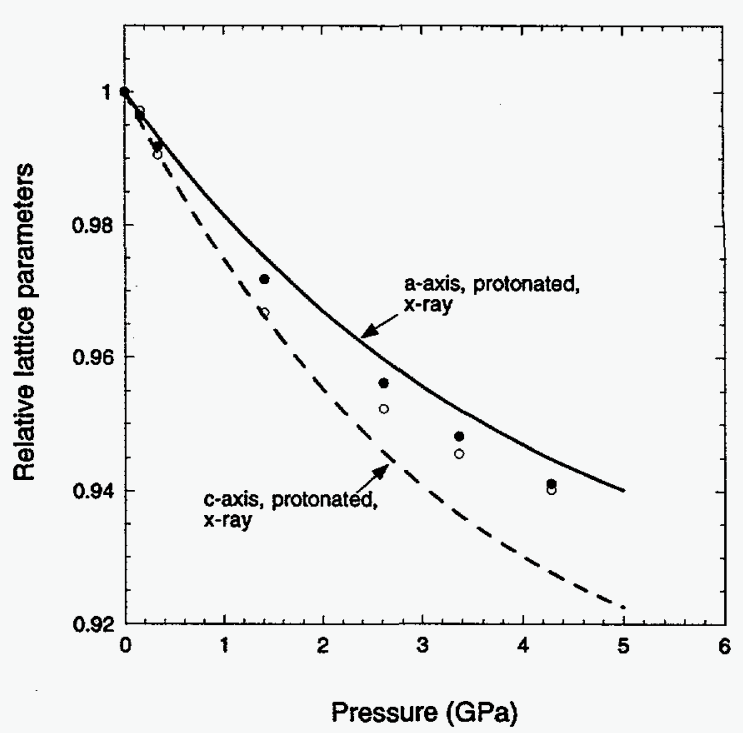

FIGURE 3. Lattice parameter changes for protonated and deuterated PETN vs pressure. The solid circles are the $d_{8}$-PETN a-axis data, and the open circles are the $d_{8}-$ PETN c-axis data from neutron experiments. The solid line is the fit to protonated, a-axis, $x$-ray data and the dashed line is the fit to protonated c-axis data of Olinger et al. The values at zero pressure are from Conant et al.

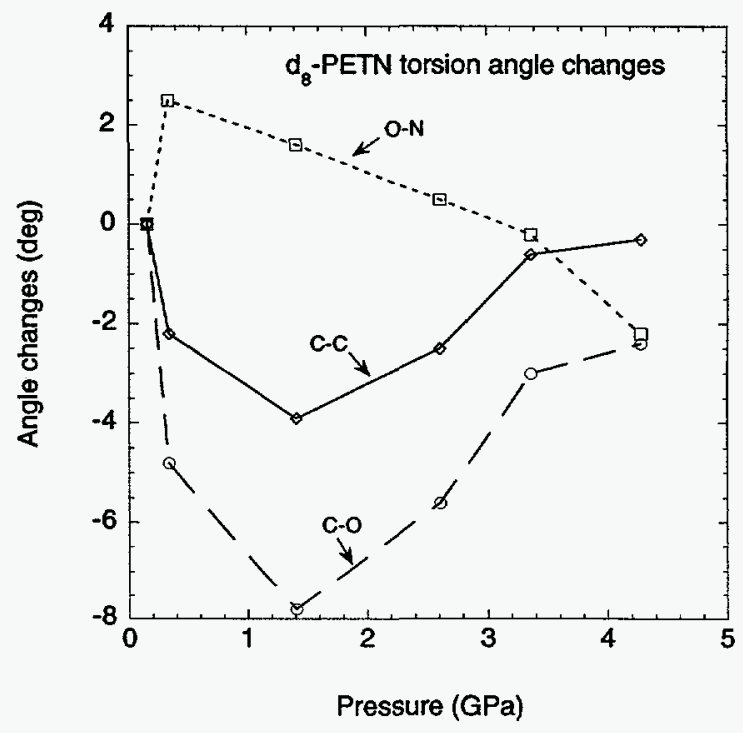

FIGURE 4. Intramolecular torsional angle changes for $d_{8}$-PETN vs pressure. The data is referenced to zero at the lowest pressure from the neutron diffraction experiments on $\mathrm{d}_{8}$-PETN, $0.154 \mathrm{GPa}$. 
Initially work was performed on $\mathrm{d}_{8}$-PETN to reduce the background signal due to incoherent scattering. This scattering is much stronger from protons than deuterons. However, since small but significant changes occurred in molecular conformation as well as molecular rotation under compression in the deuterated case, we decided to attempt to obtain similar information for protonated PETN. All the shock experiments on PETN single crystals were performed on protonated samples. Powder neutron diffraction data was obtained. There was more background, so the runs were for 24 hours instead of 12. The data has not been fully analyzed yet.

Since this work began an article has been published showing that the anomalous shock initiation sensitivity at 4 to $5 \mathrm{GPa}$ is connected with a 2-wave, elastic-plastic wave structure with large elastic precursor waves.(10) These observations are consistent with the model of initiation by sterically hindered shear during the high-strain-rate, shock compression in the plastic wave. In this case the PETN is uniaxially precompressed to about 3 $\mathrm{GPa}$ by the elastic wave before the sterically hindered shear begins. In addition to reduction of lattice parameters, some amount of molecular rotation and conformation changes must occur during this precompression. Perhaps this has the effect of enhancing the sterically hindered shear and causing more molecular excitation followed by decomposition.

\section{ACKNOWLEDGMENTS}

The deuterated PETN was prepared by Mike Coburn and Don Ott at Los Alamos a number of years ago. Elaine Hickman pressed up the pellet samples.

\section{REFERENCES}

1. J. J. Dick, R. N. Mulford, W. J. Spencer, D. R. Pettit, E. Garcia, and D. C. Shaw, J. Appl. Phys. 70, 3572 (1991).

2. P. M. Halleck and Jerry Wackerle, J. Appl. Phys. 47, 976 (1976).

3. D. Spitzer, Ph. D. thesis, Universite Louis Pasteur de Strasbourg, p. 153, 1993.

4. M. F. Foltz, in Tenth International Detonation Sympo sium, (Office of Naval Research, Arlington, VA, 1993) p. 579.

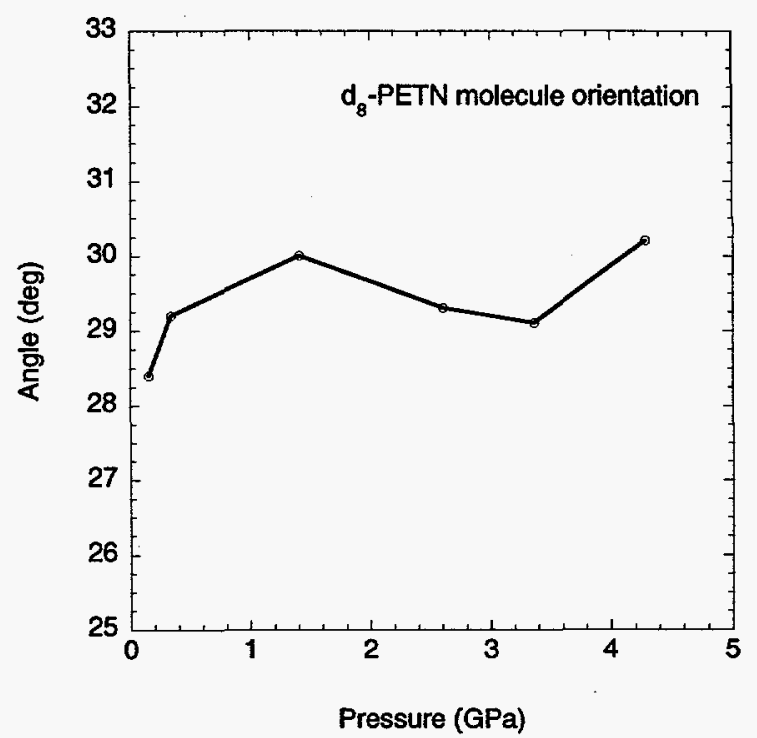

FIGURE 5. Molecular rotation for $d_{8}-P E T N$ about the $c$ axis. The angle is referenced to zero with the $\mathrm{C}-\mathrm{C}$ bond of the asymmetric unit in the a-c plane.

5. R. J. Nelmes, J. S. Loveday, R. M. Wilson, J. M. Besson, P. Pruzan, S. Klotz, and S. Hull, Phys. Rev. Letters 71, 1192 (1993).

6. R. B. von Dreele, High Pressure Res. 14, 13 (1995).

7. A. C. Larson and R. B. von Dreele, Los Alamos Report LAUR-86-748 (1994).

8. B. Olinger, P. M. Halleck and H. H. Cady, J. Chem. Phys. 62, 4480 (1975).

9. J. W. Conant, H. H. Cady, R. R. Ryan, J. L. Yarnell, and J. M. Newsam, Los Alamos Report LA-7756-MS (1979).

10. J. J. Dick, J. Appl. Phys. 81, 601 (1997). 